\title{
0xidative and pro-inflammatory lung injury induced by desflurane inhalation in rats and the protective effect of rutin
}

\author{
Mustafa Tosun ${ }^{1, A, B, D, F}$, Hasan Olmez ${ }^{1, A, B, E}$, Edhem Unver ${ }^{1, C, E}$, Yusuf Kemal Arslan ${ }^{2, C}$, \\ Ferda Keskin Cimen ${ }^{3, B, C}$, Adalet Ozcicek ${ }^{4, C, E}$, Mehmet Aktas ${ }^{5, B, C}$, Halis Suleyman ${ }^{6, A, E, F}$ \\ ${ }^{1}$ Department of Chest Diseases, Faculty of Medicine, Erzincan Binali Yildırım University, Turkey \\ ${ }^{2}$ Department of Biostatistics, Faculty of Medicine, Erzincan Binali Y.ldırım University, Turkey \\ ${ }^{3}$ Department of Pathology, Faculty of Medicine, Erzincan Binali Yıldırım University, Turkey \\ ${ }^{4}$ Department of Internal Medicine, Faculty of Medicine, Erzincan Binali Yıldırım University, Turkey \\ ${ }^{5}$ Department of Biochemistry, Faculty of Medicine, Erzincan Binali Y.ldırım University, Turkey \\ ${ }^{6}$ Department of Pharmacology, Faculty of Medicine, Erzincan Binali Yıldırım University, Turkey \\ A - research concept and design; $\mathrm{B}$ - collection and/or assembly of data; $\mathrm{C}$ - data analysis and interpretation; \\ $D$ - writing the article; $E$ - critical revision of the article; $F$ - final approval of the article
}

\section{Address for correspondence \\ Mustafa Tosun}

E-mail: dr.mustafatosun@hotmail.com

Funding sources

None declared

Conflict of interest

None declared

Received on September 26, 2020

Reviewed on March 22, 2021

Accepted on April 27, 2021

Published online on August 19, 2021

Cite as

Tosun M, Olmez M, Unver E, et al. Oxidative and pro-

inflammatory lung injury induced by desflurane inhalation in rats and the protective effect of rutin. Adv Clin Exp Med. 2021;30(9):941-948. doi:10.17219/acem/136194

DOI

10.17219/acem/136194

Copyright

Copyright by Author(s)

This is an article distributed under the terms of the

Creative Commons Attribution 3.0 Unported (CC BY 3.0)

(https://creativecommons.org/licenses/by/3.0/)

\section{Abstract}

Background. Desflurane is a mainstay of general inhaled anesthetics with a methyl ethyl ether structure and is widely used in clinical practice. It has been reported to induce inflammation and lipid peroxidation in rat pulmonary parenchyma, to increase alveolar macrophages, and to cause peribronchial infiltration and edema. Rutin, a flavonoid vitamin P1, is known to have biological properties including acting as an antioxidant, an anti-inflammatory, and an inhibitor of bronchoalveolar polymorphonuclear leukocyte (PNL) infiltration.

Objectives. The aim of this study is to examine the effects of rutin on desflurane-induced pulmonary injury using biochemical and histopathological methods.

Materials and methods. The rats were divided into 3 groups ( $n=6$ each): healthy control (HC), rutin+desflurane-treated (DRT) and desflurane-only (DSF). Briefly, $50 \mathrm{mg} / \mathrm{kg}$ of rutin was given orally to the DRT group and an equal volume of normal saline was given to the DSF and HC groups. After $1 \mathrm{~h}$, anesthesia was induced and maintained in the DRT and DSF groups for $2 \mathrm{~h}$. After the rats had been sacrificed, the lungs were removed. Malondialdehyde (MDA), total glutathione (GSH), tumor necrosis factor alpha (TNF-a), and nuclear factor kappa B (NF-KB) levels were measured in the excised lung tissue. The removed tissues were also fixed in 10\% formalin, and the obtained sections were stained with hematoxylin and eosin (H\&E) and evaluated under light microscopy. The biochemical and histopathological results of the DRT group were compared with those obtained from the DSF and HC groups.

Results. Desflurane increased MDA, TNF-a and NF-KB, and decreased GSH in lung tissue. The PNL infiltration, alveolar macrophages, hemorrhage, alveolar damage, and edema were observed in the lung tissue of the DSF group. Rutin was histopathologically shown to protect lung tissue from oxidative stress by preventing an increase in oxidant parameters and a decrease in antioxidants.

Conclusions. The results suggest that rutin may be useful in the treatment of desflurane-associated lung injury.

Key words: oxidative stress, desflurane, lung injury, rutin 


\section{Background}

Desflurane is one of the modern inhaled anesthetic drugs commonly used today that has a methyl ethyl ether structure. ${ }^{1}$ This anesthetic gas was first synthesized in the USA in the 1960s and entered into service in $1990 .^{2}$ Desflurane has been widely used because of its safety and effectiveness, as well as promoting a rapid recovery and extubation. ${ }^{1,3}$ However, like other inhalation anesthetics, desflurane affects respiration. ${ }^{4}$ The irritant effect of desflurane on the airways is much more pronounced than sevoflurane and halothane. ${ }^{5,6}$ Allaouchiche et al. have evaluated bronchoalveolar and systemic oxidative stress in animals exposed to desflurane. In their study, it was shown that desflurane accelerates the lipid peroxidation (LPO) reaction in bronchoalveolar tissue, increases the production of malondialdehyde (MDA), and induces systemic oxidative stress. ${ }^{7}$ It has also been reported that desflurane induces inflammation and LPO in rat pulmonary parenchyma, and causes peribronchial infiltration, alveolar septal infiltration and edema, and increases alveolar macrophages. ${ }^{8}$ However, the role of pro-inflammatory cytokines, such as tumor necrosis factor alpha (TNF- $\alpha)$ and nuclear factor kappa B (NF-kB), in desflurane-induced lung toxicity has not yet been examined.

Desflurane has not only been reported to cause lung injury but also severe liver injury resulting in death. ${ }^{9}$ Studies have shown that oxidative stress plays an important role in the pathogenesis of the toxic effects of desflurane in the liver. ${ }^{10}$ To date, there has not been any research examining the effects of desflurane on glutathione (GSH), which acts as a total antioxidant in lung tissue. However, while desflurane causes MDA to increase in liver tissue, the amount of total GSH decreases. ${ }^{11}$ These findings indicate that desflurane may cause oxidative and inflammatory damage in lung tissue. In addition, it can be proposed that agents that have both antioxidant and anti-inflammatory activity can protect the lungs from desflurane toxicity.

In this study, the effects of rutin (3,3,4,5,7-pentahydroxyflavone-3-rhamnoglucoside), a vitamin $\mathrm{P}_{1}$ flavonoid, on desflurane-induced lung injury were examined. ${ }^{12}$ Rutin is known to have various biological properties such as antioxidant, anti-inflammatory, antibacterial, and anti-hyperglycemic activity, cytokine inhibition, bronchoalveolar polymorphonuclear granulocyte infiltration inhibition, and immunomodulation. ${ }^{13-15}$ Rutin has also been reported to reduce lipopolysaccharide-induced oxidative acute lung injury. ${ }^{16}$ These findings indicate that rutin may be effective in reducing the lung damage induced by desflurane. At present, there are no studies that have examined the effects of rutin on desflurane-induced lung injury.

\section{Objectives}

The current study aimed to determine the harmful effects of desflurane on the lung using biochemical and histopathological methods, and to measure the protective effects of rutin, a significant antioxidant.

\section{Materials and methods}

\section{Animals}

Experimental animals were obtained from the Atatürk University Medical Experimental Application and Research Center. A total of 18 male albino Wistar rats weighing 235-248g were used in the experiments. All of the animals were kept and fed in groups in the laboratory environment $\left(22^{\circ} \mathrm{C}\right)$ before the experiment. Animal experiments were performed according to the National Guidelines for the Use and Care of Laboratory Animals, and were approved by the local animal ethics committee of Atatürk University (Erzurum, Turkey) with a decision No. 5/117, dated April 27, 2018.

This study conformed to the ethical standards laid down in the 1964 Declaration of Helsinki. The manuscript does not contain clinical studies or patient data.

\section{Chemicals}

Desflurane (Suprane 100\% inhalation steam, $240 \mathrm{~mL}$ ) was obtained from Eczacıbaşı-Baxter Hospital Supply Industry (Istanbul, Turkey) and rutin was obtained from Solgar (Leonia, USA). Each tablet contained $500 \mathrm{mg}$ of rutin ( $>94 \%$ purity).

\section{Experimental groups}

The rats were divided into 3 groups with 6 rats each: 1) healthy control (HC) group, 2) desflurane (DSF), and 3) $50 \mathrm{mg} / \mathrm{kg}$ rutin and desflurane (DRT).

\section{Preparation of rutin suspension}

In order to administer rutin at a dosage of $50 \mathrm{mg} / \mathrm{kg}$ to each animal whose average weight was $241.5 \mathrm{~g}$, the calculated dosage was found to be $12.075 \mathrm{mg}(241.5 \mathrm{~g} \times 50 / 1000$ $=12.075 \mathrm{mg}$ ). The $12.075 \mathrm{mg}$ rutin dosage was prepared for each animal as a suspension in $0.5 \mathrm{~mL}$ of a $0.9 \% \mathrm{NaCl}$ solution.

\section{Experimental procedure}

The anesthesia gas vaporizer was calibrated prior to the experiment. The anesthetic gas was adjusted according to the recommendations of Eger-Johnson and Haelwyn with a minimum alveolar concentration of $1 \%$ and a desflurane concentration of $6 \% .{ }^{17}$ Briefly, $50 \mathrm{mg} / \mathrm{kg}$ of rutin was orally administered to the DRT group $(n=6)$. The DSF $(n=6)$ and HC $(n=6)$ groups were treated orally with the same volume of normal saline $(0.5 \mathrm{~mL} 0.9 \%$ 
$\mathrm{NaCl}$ ). One hour after rutin and $0.9 \% \mathrm{NaCl}$ administration to the DRT and DSF groups, anesthesia was induced and maintained for $2 \mathrm{~h}$ in a $40 \times 40 \times 70 \mathrm{~cm}$ transparent plastic box. The box was connected to the semi-open anesthesia machine with fixed hoses. At five-minute intervals, preoxygenation was applied to the cages with $100 \%$ oxygen. Anesthesia maintenance was provided by a mixture of $2 \mathrm{~L}$ of oxygen and $2 \mathrm{~L}$ of nitrous oxide with $6 \%$ desflurane. Following this, the animals were sacrificed by decapitation and their lungs were removed. Malondialdehyde, GSH, TNF- $\alpha$, and NF- $\mathrm{kB}$ levels were measured in the excised lung tissue, and the tissues were evaluated histopathologically. The biochemical and histopathological results of the DRT group were compared with those obtained from the DSF and HC groups.

\section{Biochemical analyses}

\section{Sample preparation}

Homogenates were prepared from the lung tissues for biochemical analysis. The GSH and MDA levels in the supernatants obtained from these homogenates were determined using appropriate methods based on the literature. Briefly, $0.2 \mathrm{~g}$ was weighed from each tissue sample and removed at this stage of the study. The level of MDA in the lung tissue was determined using $1.15 \%$ potassium chloride solution, and the other measurements were carried out with phosphate buffer at $\mathrm{pH}$ 7.5. The tissue was homogenized in ice and mixed with an appropriate solution, completed to a total of $2 \mathrm{~mL} \cdot{ }^{17,18}$ The samples were then centrifuged at $4^{\circ} \mathrm{C}$ for $10 \mathrm{~min}$ at $10,000 \mathrm{rpm}$. The supernatant portion was used as the analysis sample for MDA, GSH, TNF- $\alpha$, $\mathrm{NF}-\mathrm{kB}$, and protein concentration measurements.

\section{MDA analysis}

The MDA measurement was based on a spectrophotometric measurement (at $532 \mathrm{~nm}$ ) of the absorbance of a pink colored complex formed by thiobarbituric acid (TBA) and MDA at a high temperature $\left(95^{\circ} \mathrm{C}\right) .{ }^{18}$ Briefly, $250 \mu \mathrm{L}$ of homogenate, $100 \mu \mathrm{L}$ of $8 \%$ sodium dodecyl sulfate (SDS), $750 \mu \mathrm{L}$ of $20 \%$ acetic acid, $750 \mu \mathrm{L}$ of $0.08 \% \mathrm{TBA}$, and $150 \mu \mathrm{L}$ of distilled water were mixed in Eppendorf tubes and vortexed. The mixture was then incubated at $100^{\circ} \mathrm{C}$ for $60 \mathrm{~min}$ and, once cooled down, $2.5 \mathrm{~mL}$ of n-Butanol was added. Spectrophotometric measurements were then made. The resulting red color was read using $3 \mathrm{~mL}$ cuvettes whose light path is $1 \mathrm{~cm}$ at $532 \mathrm{~nm}$. The MDA level of the samples was determined by taking the dilution coefficients into consideration and using a standard graph derived from previously prepared MDA stock solutions. The stock standard solution with a $200 \mu \mathrm{mol} / \mathrm{L}$ concentration was prepared using standard: 1.1.3.3-tetraethoxypropane. Standard solutions with different concentrations were achieved through serial dilution of the prepared stock standard.

\section{GSH analysis}

The DTNB (5,5'-Dithiobis (2-nitrobenzoic acid)), a disulfide chromogen used in the measurement medium, is decreased by compounds with sulfhydryl groups. The resulting yellow color was spectrophotometrically measured at $412 \mathrm{~nm} .{ }^{20}$ Before measurement, $0.5 \mathrm{~mL}$ of meta-phosphoric acid was added to $0.5 \mathrm{~mL}$ of the prepared supernatant and centrifuged for $2 \mathrm{~min}$ at $2000 \mathrm{rpm}$ for deproteinization. Then, $1500 \mu \mathrm{L}$ of measuring buffer $(200 \mathrm{mM}$ Tris- $\mathrm{HCl}$ containing $0.2 \mathrm{mM}$ EDTA, $\mathrm{pH}=8.2$ ), $500 \mu \mathrm{L}$ of supernatant, $100 \mu \mathrm{L}$ of DTNB, and $7900 \mu \mathrm{L}$ of methanol were mixed in Eppendorf tubes and vortexed. The mixture was incubated at $37^{\circ} \mathrm{C}$ for $30 \mathrm{~min}$ and then measured with the spectrophotometer. The amount of yellow color was read using $3 \mathrm{~mL}$ quartz cuvettes at $412 \mathrm{~nm}$, and the GSH levels in the samples were determined by taking the dilution coefficients into consideration and using a standard graph derived from a GSH stock solution prepared previously.

\section{TNF- $\alpha$ and NF-KB analysis}

Tissue-homogenate NF- $\kappa B$ and TNF- $\alpha$ concentrations were measured using rat-specific sandwich enzyme-linked immunosorbent assay kits (Rat Nuclear Factor-kappa B ELISA kit, cat. No: 201-11-0288; SunRed Biological Technology, Shangai, China; and Rat Tumor Necrosis Factor $\alpha$ ELISA kit, cat No: YHB1098Ra, Shanghai LZ, Shanghai, China). Analyses were performed according to the manufacturers' instructions. Briefly, monoclonal antibodies specific for rat NF- $\mathrm{B}$ and TNF- $\alpha$ were coated onto the wells of micro plates. The tissue homogenate, standards, biotinylated monoclonal antibody, and streptavidin-horseradish peroxidase (HRP) were pipetted into these wells and then incubated at $37^{\circ} \mathrm{C}$ for $60 \mathrm{~min}$. After washing, chromogen reagent $\mathrm{A}$ and chromogen reagent $\mathrm{B}$ were added, which is acted upon by the bound enzyme to produce a color. The samples were then incubated at $37^{\circ} \mathrm{C}$ for $10 \mathrm{~min}$ and a stop solution was added. The intensity of the colored product is directly proportional to the concentration of rat NF- $\mathrm{KB}$ and TNF- $\alpha$ present in the original specimen. At the end of the course, the well plates were read at $450 \mathrm{~nm}$. The concentration of the samples was calculated from formulas derived from standard graphs.

\section{Histopathological examination}

The removed tissues were fixed in a $10 \%$ formalin solution for $24 \mathrm{~h}$. Four micron-thick sections were obtained from the paraffin blocks using routine techniques and stained with hematoxylin and eosin (H\&E). All sections were evaluated using light microscopy (Olympus BX 52; Olympus Corp., Tokyo, Japan) by a pathologist who was not aware of the treatment protocols. 


\section{Statistical analyses}

The results for continuous variables are presented as means \pm standard deviation (SD). The normality of the distributions for continuous variables was confirmed with the Kolmogorov-Smirnov test. For the comparison of groups, one-way analysis of variance (ANOVA) was used. The homogeneity of variances was confirmed with Levene's test, and post hoc Tukey's honest significant difference (HSD) or Games-Howell tests were used according to the homogeneity of the variances. The statistical level of significance for all tests was considered to be 0.05 . Statistical analyses were performed using IBM SPSS Statistics for Windows v. 19.0 software (IBM Corp., Armonk, USA).

\section{Results}

\section{MDA and GSH analysis}

Malondialdehyde levels in the lung tissues were different across the study groups $(\mathrm{F}(2,15)=292.7, \mathrm{p}<0.001)$. Levels of MDA in the DSF group were significantly higher than the levels of healthy animals $(7.3 \pm 0.7 \mu \mathrm{mol} / \mathrm{g}$ protein compared to $1.3 \pm 0.4 \mu \mathrm{mol} / \mathrm{g}$ protein, $\mathrm{p}<0.001)$. In the DRT group, MDA levels were similar to the $\mathrm{HC}$ animals $(1.7 \pm 0.1 \mu \mathrm{mol} / \mathrm{g}$ protein compared to $1.3 \pm 0.4 \mu \mathrm{mol} / \mathrm{g}$ protein, $p>0.05$; Fig. 1). In addition, GSH levels in the lung tissues were statistically different across the study groups $(\mathrm{F}(2,15)=247.9, \mathrm{p}<0.001)$. Glutathione levels in the lung tissues of the $\mathrm{HC}$ animals were statistically higher than in the DSF rats $(5.5 \pm 0.4 \mathrm{nmol} / \mathrm{g}$ compared to $1.5 \pm 0.2 \mathrm{nmol} / \mathrm{g}$ (p < 0.001). Rutin allowed GSH levels to be maintained at $5.2 \pm 0.4 \mathrm{nmol} / \mathrm{g}$ and there was no significant difference between GSH levels in the $\mathrm{HC}$ and DRT groups ( $p$ > 0.05; Fig. 2).

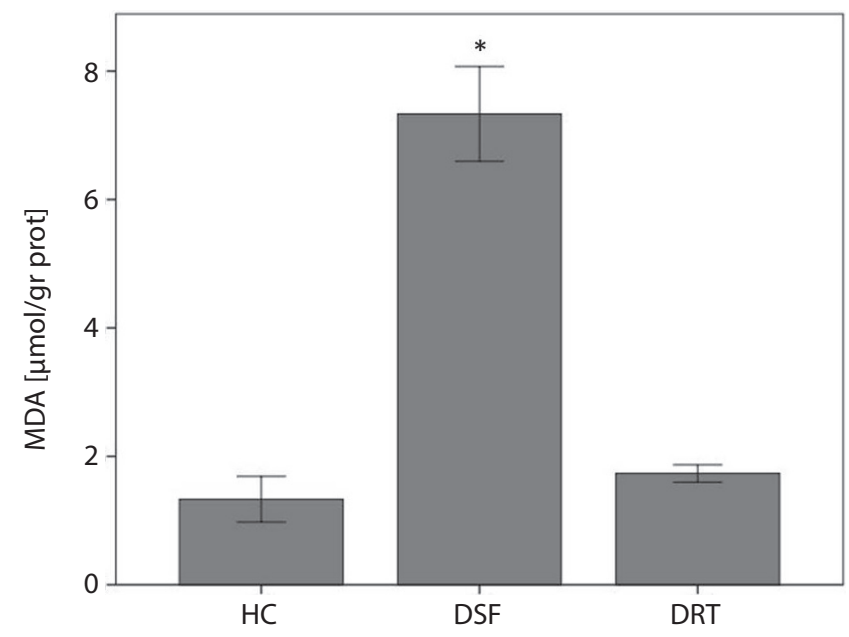

Fig. 1. Malondialdehyde (MDA) levels in the study groups; ${ }^{*} p<0.001$ when compared with healthy control group (HC). DRT - rutin+desfluranetreated group; DSF - desflurane-only group

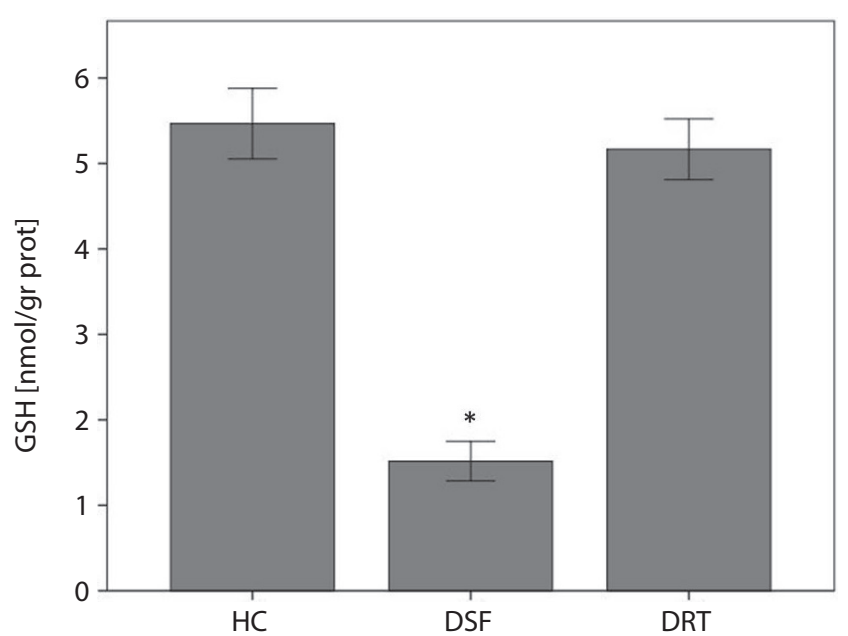

Fig. 2. Glutathione (GSH) levels in the study groups; * $p<0.001$ when compared with healthy control group (HC). DRT - rutin+desflurane-treated group; DSF - desflurane-only group

\section{TNF- $\alpha$ and NF-KB analysis}

The TNF- $\alpha$ and NF-kB levels in the lung tissues were different across the study groups $(\mathrm{F}(2,15)=250.9, \mathrm{p}<0.001$; $\mathrm{F}(2,15)=554.3, \mathrm{p}<0.001$, respectively). The TNF- $\alpha$ and NF- $\kappa$ B levels in the lung tissues of the DSF animals were both significantly higher than in the $\mathrm{HC}$ rats $(6.7 \pm 0.6 \mathrm{pg} / \mathrm{mL}$ compared to $1.8 \pm 0.3 \mathrm{pg} / \mathrm{mL}$ for TNF- $\alpha$ and $8.8 \pm 0.5 \mathrm{pg} / \mathrm{mL}$ compared to $2.7 \pm 0.3 \mathrm{pg} / \mathrm{mL}$ for NF-kB). However, rutin administration prevented the TNF- $\alpha$ and NF- $\mathrm{kB}$ levels increase induced by desflurane ( $p>0.05 ;$ Fig. 3,4 ). In the DRT group, TNF- $\alpha$ and NF- $\mathrm{kB}$ levels were similar to the $\mathrm{HC}$ animals $(2.2 \pm 0.2 \mathrm{pg} / \mathrm{mL}$ compared to $1.8 \pm 0.3 \mathrm{pg} / \mathrm{mL}$ for TNF- $\alpha$ and $3.0 \pm 0.3 \mathrm{pg} / \mathrm{mL}$ compared to $2.7 \pm 0.3 \mathrm{pg} / \mathrm{mL}$ for NF-kB).

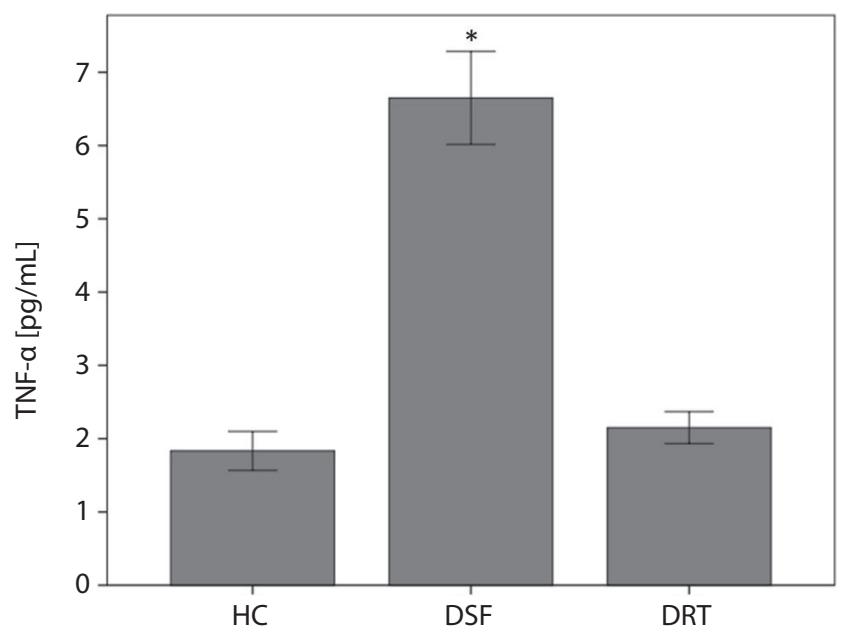

Fig. 3. Tumor necrosis factor alpha (TNF-a) levels in the study groups; ${ }^{*} \mathrm{p}<0.001$ when compared with healthy control group $(\mathrm{HC})$. DRT - rutin+desflurane-treated group; DSF - desflurane-only group 


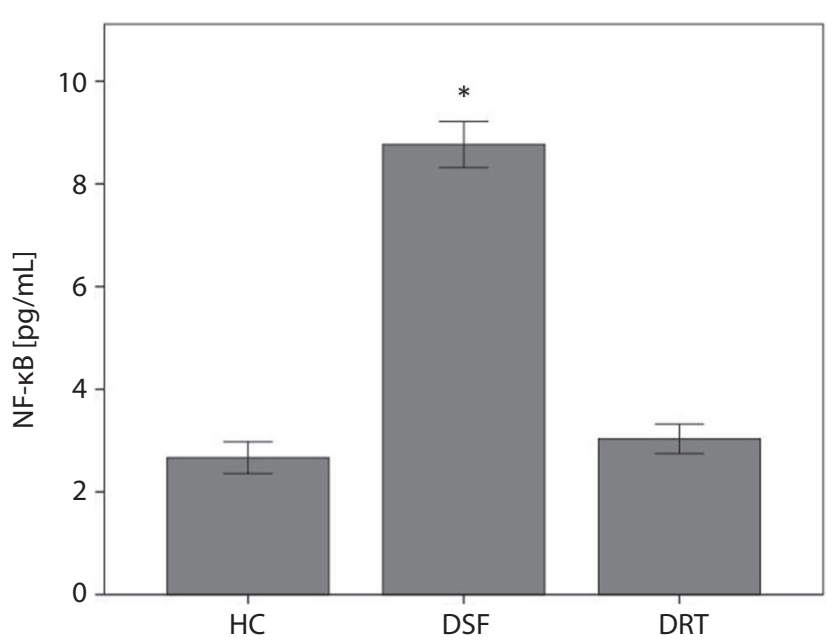

Fig. 4. Nuclear factor kappa B (NF-kB) levels in the study groups; * $p<0.001$ when compared with healthy control group $(\mathrm{HC})$. DRT - rutin+desflurane-treated group; DSF - desflurane-only group

\section{Histopathological findings}

As can be seen in Fig. 5, normal pleural mesothelium, bronchioles pulmonary arterioles and alveolar canals were observed in the lung tissues of healthy animals. On the other hand, polymorphonuclear leucocyte (PNL) infiltration, alveolar macrophages, hemorrhage, alveolar damage, and edema were observed in the lung tissue of the DSF group (Fig. 6). However, no pathological findings were reported in the lung tissue of the DRT group, with the exception of dilated conjunctival blood vessels (Fig. 7).

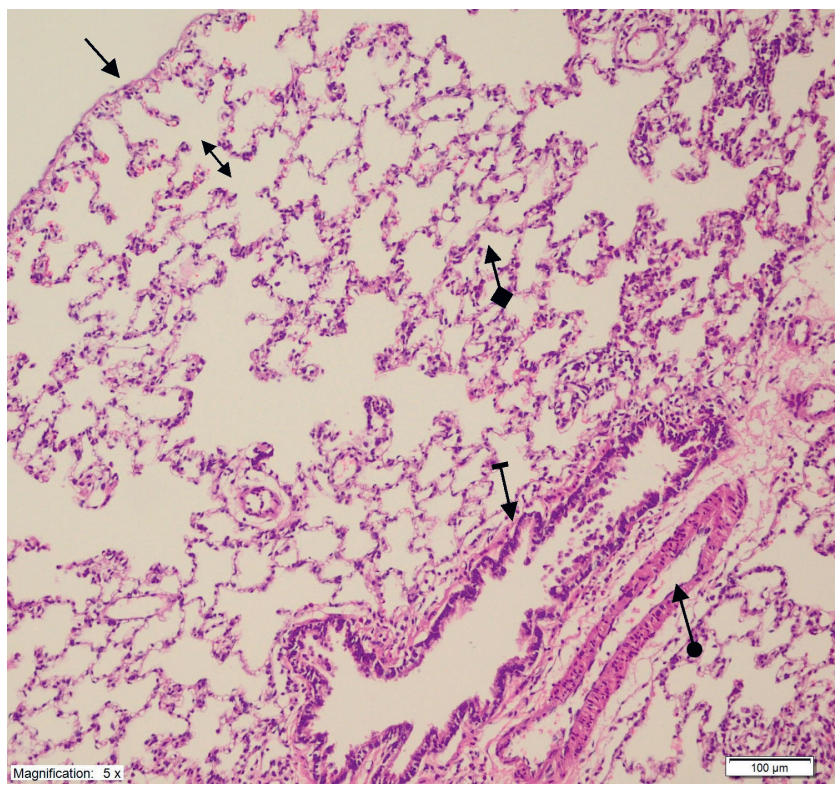

Fig. 5. Histopathological examination of the healthy control group $(\mathrm{HC})$. Normal pleural mesothelium (straight arrow), bronchioles (striped arrow), pulmonary arterioles (round arrow), alveoli (square arrow), and alveolar channels (double arrow) were observed in lung tissues of healthy animals (H\&E staining, $\times 100$ magnification)

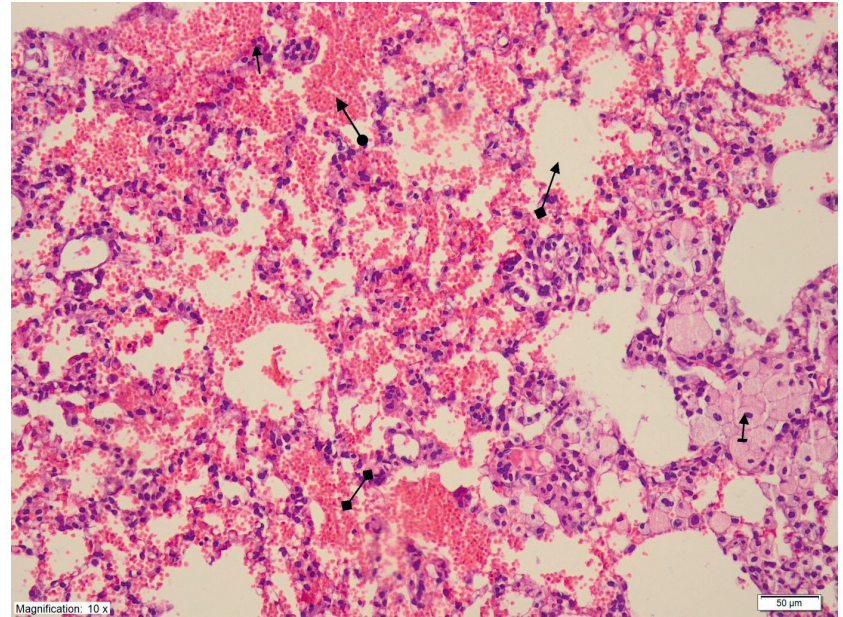

Fig. 6. Histopathological examination of the desflurane-only group (DSF). Polymorphonuclear leucocyte infiltration (straight arrow), alveolar macrophages (straight arrow), hemorrhage (round arrow), alveolar damage (double square arrow), and edema (single square) were observed in the DSF group inhaling desflurane (H\&E staining, $\times 200$ magnification)

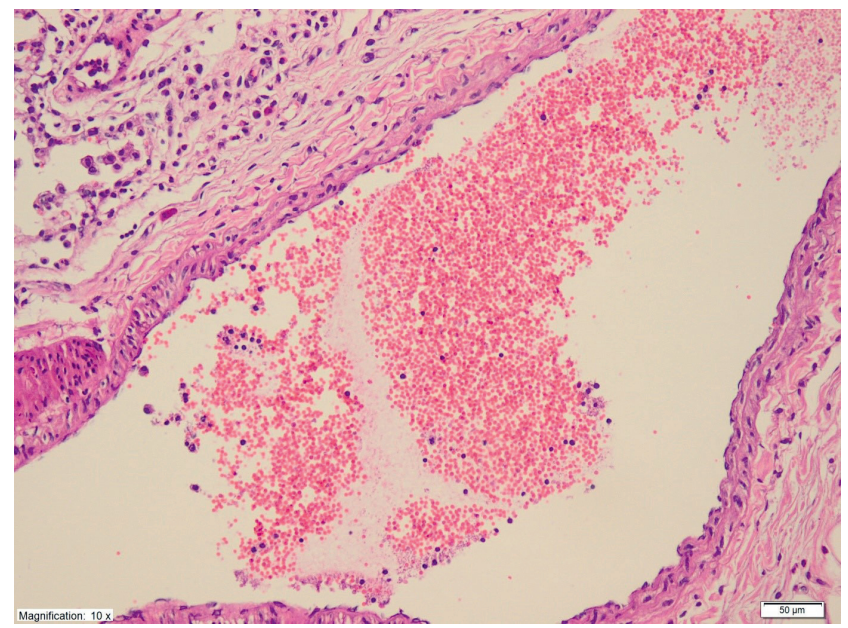

Fig. 7. Histopathological examination of the rutin+desflurane-treated group (DRT). No pathological findings except dilated conjunctival blood vessels were detected in the lung tissue of the DRT group (H\&E staining, $\times 200$ magnification)

\section{Discussion}

In this study, the effect of rutin on desflurane inhalation induced lung injury in rats was investigated biochemically and histopathologically. The biochemical results showed that, in lung tissues of the DSF animals, the levels of MDA, TNF- $\alpha$ and NF- $\mathrm{B}$ increased, and the level of GSH decreased significantly, compared to HC and DRT groups. Desflurane is a drug that provides rapid awakening when discontinued and shortens the duration of patients' stay in the recovery room. For this reason, it is one of the most commonly used modern inhaled anesthetic agents. However, when desflurane is used alone for induction of anesthesia, it irritates the respiratory tract, increases secretion, and triggers coughing and laryngospasm. ${ }^{1,2}$ Desflurane has been compared with other inhaled anesthetics in various 
studies and it has been reported that it increases oxidative stress in the lung, and causes inflammation and more lung damage than other anesthetics. ${ }^{7,21-24}$ The high MDA and low GSH levels in the lung tissues of the DSF group indicate that the oxidant/antioxidant balance changes in favor of oxidants. Under normal physiological conditions, the oxidant/ antioxidant balance is maintained in favor of antioxidants. Any change in this balance in favor of oxidants is called oxidative stress. ${ }^{25}$ Reactive oxygen species (ROS) leading to oxidative stress oxidize cell membrane lipids, facilitate the production of toxic products such as MDA from lipids, and exacerbate cellular damage. ${ }^{26,27}$ Many studies have reported that desflurane increases MDA levels and plays a role in oxidative stress. ${ }^{8,28,29}$ In the current study, MDA levels were similar between the HC group and the DRT group, but significantly elevated in the DSF group. Similar to these results, a recent study conducted by Adefegha et al. reported that rutin suppresses oxidative damage mediated by acute inflammation in rats by its anti-inflammatory activity. ${ }^{30}$

In addition, it has been shown that rutin prevents leakage of polymorphonuclear granulocytes into the bronchoalveolar lavage (BAL) fluid in LPS-induced acute lung injury (ALI). ${ }^{13,31}$ Furthermore, rutin has been shown to play a preventive role in the development of acute respiratory distress syndrome (ARDS) by increasing the secretion of pro-inflammatory cytokines and by a concentrationdependent inhibition of LPS-induced inflammatory reactions, including lipid peroxidation. ${ }^{32}$ It has also been shown that decreased superoxide dismutase, catalase and glutathione peroxidase caused by LPS, and the activities of antioxidant enzymes, such as oxygenase-1, can be reversed by rutin. ${ }^{16}$

One of the most important non-enzymatic endogenous antioxidants in cellular defense against oxidative damage is GSH. It protects the cell from ROS damage by chemically detoxifying hydrogen peroxide or organic oxides. ${ }^{33,34}$ In the current study, it was observed that GSH levels decreased in the desflurane group, whereas they were similar and maintained in the HC and DRT groups. Based on these results, it is likely that rutin, by increasing GSH levels, has preventive effects against oxidative stress.. A high GSH level is accepted as an indicator of normal cell function and viability, whereas a decrease in the GSH level is considered as a weakness of the intracellular defense system and a marker of damage. ${ }^{35}$

Furthermore, in the current study, TNF- $\alpha$ levels in the lung tissues of the DSF animals were found to be higher than that of the HC and DRT groups. The TNF- $\alpha$, which is the first detectable cytokine in the blood after tissue damage, is a glycoprotein synthesized mainly by monocytes and macrophages that can cause inflammation and tissue damage at high concentrations. ${ }^{36}$ Free oxygen radicals induced by TNF- $\alpha$ also cause edema by increasing vascular permeability, ${ }^{37}$ and pulmonary edema during septic shock occurs with this mechanism. ${ }^{38}$ It has also been reported that TNF- $\alpha$ was elevated in a patient who underwent desflurane anesthesia for ear surgery, and a systemic and intrapulmonary pro-inflammatory response developed. ${ }^{39}$ When we evaluated NF- $\mathrm{B}$ levels, it was found that NF-kB levels were increased in the DSF group, and that the $\mathrm{HC}$ and DRT groups showed similar levels of TNF- $\alpha$. Increased NF- $\mathrm{kB}$ in the DSF group and similar levels in the $\mathrm{HC}$ and DRT groups can be considered an indicator of the antiinflammatory effects of flavonoids. Studies have also shown that abnormal activation and inhibition of NF-kB plays a role in the pathophysiological processes of many diseases such as metabolic, inflammatory and neurodegenerative diseases, and cancer. ${ }^{40}$ Resveratrol, a flavonoid in red wine, also inhibits NF- $\mathrm{B}$ activity. Accordingly, it is thought that resveratrol can reduce the mortality rates of coronary heart diseases and some types of cancer. ${ }^{41}$ Lee et al. reported that TNF- $\alpha$ released from endothelial cells stimulated by LPS and subsequently activated NF- $\mathrm{kB}$ are suppressed by rutin in a dose-dependent manner, suggesting that rutin may be useful in vascular inflammatory diseases. ${ }^{42}$

In the current study, the biochemical results were also supported by histopathological findings. In a study by Aldemir et al. evaluating the effects of desflurane and isoflurane on the lung histopathologically, the degree of peribronchial inflammatory infiltration and the number of alveolar macrophages were significantly higher in the desflurane group. In addition, alveolar septal infiltration and edema were detected together with high MDA levels. ${ }^{8}$ Others have examined changes in the rabits' lungs after human recombinant TNF- $\alpha$ injection, and increased vascular permeability, granulocyte infiltration and edema were found.$^{37}$ In this study, PNL infiltration, alveolar macrophages, hemorrhage, alveolar damage, and edema were observed in lung tissues of the DSF group. It is likely that these findings are due to the increase in TNF- $\alpha, N F-\kappa B$ and MDA levels in lung tissue. Many studies have been conducted on the preventive effect of rutin against lung injury caused by LPS. ${ }^{31,43}$ Histopathological examination in LPS-induced ALI revealed that rutin prevented PNL infiltration, which is expected to be the dominant cell in BAL fluid, and had a protective effect against ALI. ${ }^{43}$ Others have shown that rutin has a preventive effect against ARDS by inhibiting lipid peroxidation. ${ }^{32}$ Similar to these studies, no histopathologic findings, except for dilated conjunctival blood vessels, were found in the DRT group in our study. We believe that this is proof of the protective effect of rutin.

\section{Limitations}

In order to explain the mechanisms of lung damage caused by desflurane in more detail, total oxidant, total antioxidant and anti-inflammatory cytokine levels should be measured, and the effect of rutin on these parameters should be investigated. In addition, it will be important to examine the molecular histopathology of the tissues. 


\section{Conclusions}

The results indicate that desflurane inhalation increases MDA, TNF- $\alpha$ and NF- $\kappa B$, factors associated with inflammation and oxidative stress, and decreases GSH, a strong antioxidant, in lung tissues of rats. Administration of rutin reversed the effects of desflurane on these parameters and eliminated oxidative stress, showing a protective effect on lung tissue. Our experimental results showed that the biochemical and histopathological effects were consistent. We consider that these results will shed light on future studies investigating the protective effect of rutin on the lungs.

\section{ORCID iDs}

Mustafa Tosun (1) https://orcid.org/0000-0002-5204-2099 Hasan Olmez (1) https://orcid.org/0000-0003-4153-9953 Edhem Unver (1) https://orcid.org/0000-0002-0322-8102 Yusuf Kemal Arslan (1) https://orcid.org/0000-0003-1308-8569 Ferda Keskin Cimen (1) https://orcid.org/0000-0002-1844-0827 Adalet Ozcicek (1) https://orcid.org/0000-0003-3029-4524 Mehmet Aktas (1) https://orcid.org/0000-0003-1931-8353 Halis Suleyman (10) https://orcid.org/0000-0002-9239-4099

\section{References}

1. Jakobsson J. Desflurane: A clinical update of a third-generation inhaled anaesthetic. Acta Anaesthesiol Scand. 2012;56(4):420-432. doi:10. 1111/j.1399-6576.2011.02600.x

2. Bedi A, Howard Fee JP. Inhalational anaesthesia. Curr Opin Anaesthesiol. 2001;14(4):387-392. doi:10.1097/00001503-200108000-00002

3. Meco M, Cirri S, Gallazzi C, Magnani G, Cosseta D. Desflurane preconditioning in coronary artery bypass graft surgery: A double-blinded, randomised and placebo-controlled study. Eur J Cardiothoracic Surg. 2007;32(2):319-325. doi:10.1016/j.ejcts.2007.05.005

4. MS Sheller. New volatile anaesthetics: Desflurane-sevoflurane. Semin Anaesth. 1992;(11):114-122.

5. Stoelting RK. Pharmacology and physiology in anaesthetic practice. In: Pharmacology and Physiology in Anaesthetic Practice. $3^{\text {rd }}$ ed. Philadelphia, USA: Lippincott-Raven Publishers; 1999:47-123.

6. Taylor RH, Lerman J. Induction, maintenance and recovery characteristics of desflurane in infants and children. Can J Anaesth. 1992;39(1): 6-13. doi:10.1007/BF03008665

7. Allaouchiche B, Debon R, Goudable J, Chassard D, Duflo F. Oxidative stress status during exposure to propofol, sevoflurane and desflurane. Anesth Analg. 2001;93(4):981-985. doi:10.1097/00000539200110000-00036

8. Aldemir T, Turan S, Gomceli I, et al. A comparison of the effects of desflurane and isoflurane on rat pulmonary parenchyme histopathology and malondialdehyde levels. J Pak Med Assoc. 2012;62(11):1174-1178. PMID:23866405

9. Lin J, Moore D, Hockey B, et al. Drug-induced hepatotoxicity: Incidence of abnormal liver function tests consistent with volatile anaesthetic hepatitis in trauma patients. Liver Int. 2014;34(4):576-582. doi:10.1111/liv.12278

10. Arslan M, Isik B, Kavutcu M, Kurtipek O. Effects of desflurane on oxidant/ antioxidant status of female young versus old rat liver tissues. J Anim Vet Adv. 2010;9(19):2502-2507. doi:10.3923/javaa.2010.2502.2507

11. Arslan A, Kuyrukluyildiz U, Binici O, et al. Can thiamıne pyrophosphate prevent desflurane induced hepatotoxicity in rats? Acta Cir Bras. 2016;31(3):168-175. doi:10.1590/S0102-865020160030000004

12. Harborne JB. Nature, distribution and function of plant flavonoids. Prog Clin Biol Res. 1986;213:15-24. PMID:3520585

13. Ganeshpurkar A, Saluja AK. The pharmacological potential of rutin Saudi Pharm J. 2017;25(2):149-164. doi:10.1016/j.jsps.2016.04.025

14. Singh $H$, Kaur $P$, Kaur $P$, Muthuraman A, Singh G, Kaur M. Investigation of therapeutic potential and molecular mechanism of vitamin P and digoxin in I/R-induced myocardial infarction in rat. Naunyn Schmiedebergs Arch Pharmacol. 2015;388(5):565-574. doi:10.1007/ s00210-015-1103-8
15. Kamalakkannan N, Prince PSM. Antihyperglycaemic and antioxidant effect of rutin, a polyphenolic flavonoid, in streptozotocin-induced diabetic wistar rats. Basic Clin Pharmacol Toxicol. 2006;98(1):97-103. doi:10.1111/j.1742-7843.2006.pto_241.x

16. Yeh CH, Yang JJ, Yang ML, Li YC, Kuan YH. Rutin decreases lipopolysaccharide-induced acute lung injury via inhibition of oxidative stress and the MAPK-NF-kB pathway. Free Radic Biol Med. 2014;69:249-257. doi:10.1016/j.freeradbiomed.2014.01.028

17. Eger El, Johnson $\mathrm{BH}$. MAC of I-653 in rats, including a test of the effect of body temperature and anesthetic duration. Anesth Analg. 1987;66(10):974-976. doi:10.1213/00000539-198710000-00009

18. Ohkawa H, Ohishi N, Yagi K. Assay for lipid peroxides in animal tissues by thiobarbituric acid reaction. Anal Biochem. 1979;95(2):351-358. doi:10.1016/0003-2697(79)90738-3

19. Weydert CJ, Cullen JJ. Measurement of superoxide dismutase, catalase and glutathione peroxidase in cultured cells and tissue. Nat Protoc. 2010;5(1):51-66. doi:10.1038/nprot.2009.197

20. Sedlak J, Lindsay RH. Estimation of total, protein-bound, and nonprotein sulfhydryl groups in tissue with Ellman's reagent. Anal Biochem. 1968;25(1):192-205. doi:10.1016/0003-2697(68)90092-4

21. Musacchio E, Rizzoli V, Bianchi M, Bindoli A, Galzigna L. Antioxidant action of propofol on liver microsomes, mitochondria and brain synaptosomes in the rat. Pharmacol Toxicol. 1991;69(1):75-77. doi:10.1111/ j.1600-0773.1991.tb00414.x

22. Murphy PG, Myers DS, Davies MJ, Webster NR, Jones JG. The antioxidant potential of propofol (2,6-diisopropylphenol). Br J Anaesth. 1992;68(6):613-618. doi:10.1093/bja/68.6.613

23. Acat C, Erol A, Topal A, Reisli R, Reisli I, Otelcioğlu Ş. Bronkoalveolar Lavaj (Bal) Sıvısındaki Nötrofillerin Kemotaktik Fonksiyonları Üzerine Sevofluran, Desfluran ve Propofol Anestezisinin Etkileri. Türk Anest Rean Der. 2007;35(6):413-419.

24. Strosing KM, Faller S, Gyllenram V, et al. Inhaled anesthetics exert different protective properties in a mouse model of ventilator-induced lung injury. Anesth Analg. 2016;123(1):143-151. doi:10.1213/ANE.00000 00000001296

25. Kisaoglu A, Borekci B, Yapca OE, Bilen H, Suleyman H. Tissue damage and oxidant/antioxidant balance. Eurasian J Med. 2013;45(1):47-49. doi:10.5152/eajm.2013.08

26. Kanner J, German JB, Kinsella JE, Hultin HO. Initiation of lipid peroxidation in biological systems. Crit Rev Food Sci Nutr. 1987;25(4): 317-364. doi:10.1080/10408398709527457

27. Dalle-Donne I, Rossi R, Giustarini D, Milzani A, Colombo R. Protein carbonyl groups as biomarkers of oxidative stress. Clin Chim Acta. 2003;329(1-2):23-38. doi:10.1016/s0009-8981(03)00003-2

28. Turkan H, Aydin A, Sayal A, Eken A, Akay C, Karahalil B. Oxidative and antioxidative effects of desflurane and sevoflurane on rat tissue in vivo. Arh Hig Rada Toksikol. 2011;62(2):113-119. doi:10.2478/100041254-62-2011-2096

29. Koksal GM, Sayilgan C, Aydin S, Uzun H, Oz H. The effects of sevoflurane and desflurane on lipid peroxidation during laparoscopic cholecystectomy. Eur J Anaesthesiol. 2004;21(3):217-220. doi:10.1017/ s0265021504003102

30. Adefegha SA, Leal DBR, De Oliveira JS, Manzoni AG, Bremm JM. Modulation of reactive oxygen species production, apoptosis and cell cycle in pleural exudate cells of carrageenan-induced acute inflammation in ratsby rutin. Food Funct. 2017;8(12):4459-4468. doi:10.1039/ C7FO01008G

31. Chen WY, Huang YC, Yang ML, et al. Protective effect of rutin on LPSinduced acute lung injury via down-regulation of MIP-2 expression and MMP-9 activation through inhibition of Akt phosphorylation. Int Immunopharmacol. 2014;22(2):409-413. doi:10.1016/j.intimp. 2014.07.026

32. Ortolani O, Conti A, De Gaudio AR, Masoni M, Novelli G. Protective effects of $\mathrm{N}$-acetylcysteine and rutin on the lipid peroxidation of the lung epithelium during the adult respiratory distress syndrome. Shock. 2000;13(1):14-18. doi:10.1097/00024382-200013010-00003

33. Meister A, Anderson ME. Glutathione. Annu Rev Biochem. 1983;52(1): 711-760. doi:10.1146/annurev.bi.52.070183.003431

34. Akbari M, Ostadmohammadi V, Lankarani $\mathrm{K}$, et al. The effects of vitamin $D$ supplementation on biomarkers of inflammation and oxidative stress among women with polycystic ovary syndrome: A systematic review and meta-analysis of randomized controlled trials. Horm Metab Res. 2018;50(04):271-279. doi:10.1055/s-0044-101355 
35. Santa T. Recent advances in analysis of glutathione in biological samples by high-performance liquid chromatography: A brief overview. Drug Discov Ther. 2013;7(5):172-177. PMID:24270380

36. Vilcek J. First demonstration of the role of TNF in the pathogenesis of disease. J Immunol. 2014;181(1):5-6. doi:10.4049/jimmunol.181.1.5

37. Goldblum SE, Hennig B, Jay M, Yoneda K, McClain CJ. Tumor necrosis factor a-induced pulmonary vascular endothelial injury. Infect Immun. 1989;57(4):1218-1226. doi:10.1128/iai.57.4.1218-1226.1989

38. Maury CP, Teppo AM. Circulating tumour necrosis factor-alpha (cachectin) in myocardial infarction. JIntern Med. 1989;225(5):333-336. doi:10.1111/j.1365-2796.1989.tb00090.x

39. Koksal GM, Sayilgan C, Gungor G, et al. Effects of sevoflurane and desflurane on cytokine response during tympanoplasty surgery. Acta Anaesthesiol Scand. 2005;49(6):835-839. doi:10.1111/j.1399-6576. 2005.00677.x
40. Camandola S, Mattson MP. NF-kappa B as a therapeutic target in neurodegenerative diseases. Expert Opin Ther Targets. 2007;11(2):123-132. doi:10.1517/14728222.11.2.123

41. Yamamoto Y, Gaynor RB. Therapeutic potential of inhibition of the NF-kB pathway in the treatment of inflammation and cancer. J Clin Invest. 2001;107(2):135-142. doi:10.1172/JCl11914

42. Lee W, Yoo H, Kim JA, et al. Barrier protective effects of piperlonguminine in LPS-induced inflammation in vitro and in vivo. Food Chem Toxicol. 2013;58(9):149-157. doi:10.1016/j.fct.2013.04.027

43. Yeh $\mathrm{CH}$, Yang JJ, Yang ML, Li YC, Kuan YH. Rutin decreases lipopolysaccharide-induced acute lung injury via inhibition of oxidative stress and the MAPK-NF-kB pathway. Free Radic Biol Med. 2014;69:249-257. doi:10.1016/j.freeradbiomed.2014.01.028 